\title{
Deyimlerin Öğrenilmesi ve Kalıcılığında Animasyonların Etkisi
}

\author{
Kadir Kaan Büyükikiz*, Onur Dölek**, Fatma Kızdırıcı***
}

Makale Geliş Tarihi: 01/10/2018

Makale Kabul Tarihi: 27/11/2018

DOI: $10.35675 /$ befdergi.466127

$\ddot{\boldsymbol{O}} z$

Bu çalışmanın amacl, animasyonların deyim öğrenimi ve kalıcllı̆̆ üzerindeki etkisini belirlemektir. Araştırmada karma desen benimsenmiştir. Araştırmanın çalışma grubunu 2017 2018 ögretim yılında beşinci sinıfa devam eden 130 öğrenci oluşturmaktadır. Deyimlerin ögretilmesi sürecinde deney grubuna animasyonlarla desteklenmiş ögrrenme ortamı sunulmuş; kontrol grubunda ise geleneksel yaklaşım çerçevesinde sadece düz anlatım tekniğinden yararlanılmıştır. Araştırmada çoktan seçmeli deyim testi ve yarı yapılandırılmış görüşme formu kullanılmıştır. Nicel verilerin çözümlenmesinde Mann-Whitney U testi ve Wilcoxon İşaretli Siralar testi; nitel verilerin çözümlenmesinde betimsel çözümleme yöntemi kullanılmıştır. Yapılan istatistiksel çözümlemeler sonucunda, animasyonların deyim öğrenimini olumlu yönde ve anlamlı düzeyde etkilediği; buna karşın geleneksel anlayışla yapılan ögretimin deyim öğrenimi üzerinde anlamlı bir etkisinin olmadiğı bulgusuna ulaşılmıştır. Araştırmadan elde edilen diğer bir sonuç, animasyonların deyim bilgisinde kalıcılı̆̆ı sağladı̆̆ yönündedir. Ayrıca araştırmaya katılan deney grubu ögrrencilerinin büyük bir çoğunluğu, animasyonların deyim ögrenimlerine olumlu yönde katkısının olduğu (\%89) ve derse karşı ilgilerini artırdiğl (\%86) yönünde görüş bildirmiştir.

Anahtar Kelimeler: Animasyon, deyim, ögretim

\section{The Effects of Animations on Idiom Learning and Permanence of the Idioms}

\begin{abstract}
The purpose of this study is to determine the effect of animation on learning idioms and permanence of the idiom. The mixed method design was used. The sample group of the research study is composed of 130 students who are in fifth grade in the academic year of 2017-2018. Throughout the process of teaching idioms, a learning environment supported with animations was provided for the experimental group and the direct narrative technique within the framework of the traditional approach was utilized in the control group. Multiple choice test was utilized and semi-structured interview form was used. The Mann-Whitney U test and the Wilcoxon Marked Rank test were used to analyse the quantitative data obtained; descriptive analysis method was used in the analysis of the qualitative data. As a result of the statistical analyses, it was found that the animations had a positive and statistically significant effect on

\footnotetext{
*Gaziantep Üniversitesi, Nizip Eğitim Fakültesi, Sosyal Bilimler ve Türkçe Eğitimi Bölümü, Gaziantep, Türkiye, kbuyukikiz@gmail.com, ORCID: 0000-0001-6727-0273

**B Bolu Abant İzzet Baysal Üniversitesi, Eğitim Bilimleri Enstitüsü, Türkçe Eğitimi Bölümü, Bolu, Türkiye, onur.dolek@ hotmail.com, ORCID: 0000-0002-8816-2754

${ }^{* * * *}$ Gaziantep Üniversitesi, TÖMER, Gaziantep, Türkiye, ftmkzdrc@ gmail.com, ORCID: 0000-0002-79220553
}

Kaynak Gösterme: Büyükikiz K.K., Dölek, O. ve Kızdırıcı, F. (2019). Deyimlerin öğrenilmesi ve kalıcılığında animasyonların etkisi. Bayburt Eğitim Fakültesi Dergisi, 14(27), 53-70. https://doi.org/10.35675/befdergi.466127 
idiom learning; however, it has been found that there is no effect on the idiomatic learning of teaching by traditional understanding. Another result obtained from the research is that animations provide persistence in idiomatic knowledge. In addition, a large majority of the students in the experimental group who participated in the research study stated that the animations contributed positively to idiom learning (89\%) and that their interest on class increased (86\%).

Keywords: Animation, idiom, teaching

\section{Giriş}

Teknolojik gelişmeler, farklı öğrenme sitillerine sahip öğrencilerin özelliklerine uygun öğretim materyallerinin tasarlanmasını sağlamaktadır. Bu materyaller, öğretim içeriklerini zenginleştirerek içeriğe ulaşılabilirliği kolaylaştırmakta ve öğrenmeöğretme sürecinin daha etkin gerçekleşmesine imkân tanımaktadır. Bu bağlamda animasyonlar, film makinesi, televizyon ve videolar hem görsel hem de işitsel ortamlar arasında gösterilebilir. Bu tür eğitim ortamları birden fazla duyuya hitap eden dolayısı ile birden fazla veri türünü kapsayan ortamlar olarak öne çıkmakta ve çoklu ortam olarak adlandirılmaktadır (Akkoyunlu ve Yılmaz, 2005).

Dil öğreniminde teknoloji kullanımı gelişmiş öğrenme yaşantıları sağlaması bakımından oldukça önemlidir. Teknoloji; dil öğrenme deneyimlerini geliştirdiği gibi dilin doğasını, anlayışımızı yeniden biçimlendirmeye de katkı sunar. Aslında dil öğrenimini ve kültürü etkileyen teknolojinin kendisi değildir; teknolojinin özel kullanımıdır. Bu nedenle öğretmen, öğrencilerin teknoloji yardımıyla dil edinimlerini sağlayacak etkinlikler planlamalıdır. Böylelikle öğrenciler gerçek dil kullanımıyla karşı karşıya getirilmiş olur (Freeman ve Anderson, 2014). Böyle bir ortamda birey çevresiyle etkileşim kurar; özümseme ve düzenleme gibi süreçleri kullanarak aktif bir şekilde bilgiyi yapılandırır. Var olan şemalarından hareketle yeni deneyimlerin kendilerinde nasıl bir bilgi ağı oluşturabileceğini öğrenir. Birey öğrenme faaliyetlerine girdikçe bilinen ve alışılmış bilgi sistemlerinin dişında yeni ögeler öğrenip keşfeder (Tompkins, 2005). Bu nedenle bireyin bilişsel şemalarında var olan bilgileri harekete geçirerek yeni öğrenmelere olanak tanınması için birden fazla duyu organına hitap eden öğrenme ortamları oluşturulmalıdır. Bir başka deyişle bireyin çevresiyle etkileşim kurabileceği öğrenme ortamı sağlanmalıdır. Böylelikle yeni öğrenmeler için bilişsel şemaların harekete geçirilmesi kolaylaşır.

Bilgisayar teknolojisindeki hızlı ilerlemeye koşut olarak animasyon, ses, grafik ve metin gibi multimedya teknolojilerinin eğitim ortamında kullanılması da artmaktadır. $\mathrm{Bu}$ da öğrenme işlemlerindeki çeşitlilikler ile öğrencilere daha zengin eğitsel çevreler sunarak eğitim ve öğretimin yeniden düzenlenmesini sağlamaktadır (Daşdemir ve Doymuş, 2012). Ses, video veya animasyonların bir araya getirilmesiyle oluşturulan çoklu ortam, yenilikçi yöntemler ve materyaller sayesinde, dil öğrenme ortamlarının daha renkli, motive edici ve aynı zamanda öğrenim sürecinde öğrenciler için daha fazla destekleyici olmasına yardım eder (Lowe, 2004). 
Günümüzde bilgisayar çoklu ortam araçlarını (resim gösterme, video/ses/animasyon oynatma, web sayfaları) etkin olarak dersin işlenişinde kullanmak olanaklıdır. Bu tür araçlar kullanıcıya ve uygulayıcıya birebir etkileşim olanağı vererek motivasyonu artırdığından, konuların öğretilmesinde oldukça etkilidir. Bunun yanında uzun bilgi aktarımları sonunda her zaman öğrenmenin hedeflerine ulaşılamayabilir. Buna karşın konuyu özetleyen bir animasyonla kısa süre içerisinde bilgiler açık ve net olarak iletilebilir (Güvercin, 2010).

\section{Animasyon}

Animasyon; bilgisayar görüntülerinin ayrıntılı çizimlerle boyutlandırılmış canlı yapımıdır. Animasyonlar bazı durumların ortaya çıktığını ya da yok olduğunu, şekillerin veya renklerin değişmeye uğradığını gösterir. Bu değişiklikler grafik olabileceği gibi resim ve karikatür de olabilmektedir (Laybourne, 1998; akt. Daşdemir ve Doymuş, 2012). Bir başka deyişle animasyon birçok resim ve grafiğin senaryolar içerisinde hareketlendirilmesidir (Güvercin, 2010). Animasyonlar aracilığıyla öğretimsel bir içerik, resimlerin ve kelimelerin zaman ya da mekân içerisinde peş peşe sunulmasıyla etkili bir biçimde öğretilebilir (Mayers ve Anderson, 1992). Animasyonlar, soyut konuların görsel bir zenginlikle somutlaştırılması ve etkileşimli öğrenmeye zemin hazırlaması açısından önemlidir. Ayrıca birden fazla bilgiyi veya iletiyi aynı zaman dilimi içerisinde verebilme ve istenen zamanda bilgileri tekrar edebilme firsatı sunar (Göçmenler, 2002).

Animasyon gösterilerinde amaç, öğrencilerin düz anlatımın ötesinde daha kalıcı bir öğrenme gerçekleştirmelerini sağlamaktır. $\mathrm{Bu}$ yöntemin temel mantığ animasyonla yapılan anlatımların, düz sunumla gerçekleştirilen anlatımlardan daha etkili sonuçlar doğurmasına dayanmaktadır. Bu durumda öğrenciler sözcükler ve resimler arasında akıl bağlantıları kurabilir ve zihinsel işlemleme sürecini hızlandırabilir. Buna rağmen her animasyon konu öğretiminde aynı derecede etkili olmayabilir. Bu nedenle konuya uygun animasyon seçimi yapılmalı, animasyonun etkili olan ve olmayan yönleri belirlenerek uygulanmaya karar verilmelidir. Öte yandan animasyonların tek başına sözel anlatımdan daha etkili olduğu çoklu ortam anlayışı doğrultusunda kanıtlanmıştır. Nitekim yapılan bir çalışmada araba parçalarının işlevlerinin animasyon eşliğinde daha iyi kavrandığı sonucuna ulaşılmıştır (Mayer ve Moreno, 2002).

\section{Deyim}

Dil, kültürün temel taşıyıcısı ve vazgeçilmez ögesidir. Ulusa özgü, duygu ve düşünce birliğinin oluşturduğu ortak ruh olan kültürü en iyi aktaran, taşıyan sistem de dildir (Sağır ve Atalay, 2016, s. 1). Ulusa özgü duygu ve düşüncelerin oluşturduğu ortak ruhun en iyi açıklayıcılarından biri, bir ulusun söz varlığı içerisinde yer alan ve kültürün temel taşıyıcıları olan deyimlerdir. 
Deyimler, halkın söz yaratma gücünü, ifade zenginliğini ortaya koyar. Deyimlerin arkasında çok uzun yıllar süren bir yaşanmışlık ve gözlemler toplamı vardır (Bulut, 2017, s. 9). Bu bağlamda deyimler; bir olayı, bir durumu, bir kavramı daha etkileyici anlatmak için en az iki sözcüğün bir araya gelmesiyle oluşan ve genellikle gerçek anlamından uzaklaşıp kendine özgü anlam kazanan söz gruplarıdır (Şirin vd., 2017). Deyimler, anlaşılması güç ve yapısal olarak değiştirilemeyen birden fazla sözcükten oluşan basmakalıp anlam birimleridir (Langlotz, 2006).

Deyimler, kendisini oluşturan sözcüklerin anlamları toplamından daha fazla anlamı olan ifadelerdir (McCarthy, O'Keeffe ve Walsh, 2010). Çekici, çarpıcı, yoğun bir anlatım özelliği taşıyan deyimlerin işlevi anlatımı güçlendirmek, güzelleştirmektir (Bilgin, 2013). Deyimlerin anlamı, kendisini oluşturan sözcüklerin anlamlarına bakılarak elde edilemez (Cacciari ve Tabossi, 1988). Yani deyimleri oluşturan sözcükler bütün olarak tek bir kavramı karşılar. Bu bakımdan deyim içerisinde yer alan sözcüklerin anlamlarını birbirinden bağımsız ve temel anlamlarıyla düşünmek olanaklı değildir.

Deyimler, öğrencilerin gözünde öğrenilmesi ve etkin bir biçimde kullanılması zor ifadeler olarak görülmektedir. Geniş sözcük dağarcı̆̆ına sahip ve dil bilgisi kurallarına hâkim bireyler bile deyimlerle ilgili sorunlar yaşamaktadır. Yapılan araştırmalarda deyimlerin birçok anadil kullanıcısı tarafından yanlış bağlamda kullanıldığı ve anadil konuşurlarının deyim kullanmaktan kaçındığı vurgulanmaktadır (Arnaud ve Savignon, 1997; akt. McCarthy, O'Keeffe ve Walsh, 2010, s. 69; Kellerman, 1986; Yorio, 1989). Bu durum deyimlerin özel anlamlı işlevlerinden, anlaşılması ve özellikle doğru anlamda kullanılması zor ifadeler olmasından kaynaklanmaktadır.

Yukarıdaki düşüncelere koşut olarak deyimlerin günlük dil kullanımında gereksinim duyulan ifadeler olduğu yönünde artan farkındalık ve bu yapıların hem alıcı dil hem de ifade edici dil becerileri üzerindeki önemli rolü, uygulayıcıların deyim öğretimi üzerinde önemle durmasını zorunlu kılmaktadır. Bu bağlamda teknolojik gelişmelerin bir parçası olarak animasyon kullanımının deyim öğrenimi üzerindeki etkisini belirlemenin temel dil becerilerinin geliştirilmesi sürecinde uygulayıcılara yol gösterici olabileceği düşünülmektedir. Ayrıca alan yazın incelendiğinde çoklu ortam araçlarının (animasyon, çizgi film vb.) dil becerileri üzerindeki etkisini sınayan (Ünal ve Bursalı, 2015; Y1lmaz ve Talas, 2015), deyimlerin kullanımı ve öğretimi üzerinde duran (Bayat ve Çetinkaya, 2014; Güneş, 2009; Tran, 2012; Williams, Bannister, Arribas-Ayllon, Preece ve Spasic, 2015; Yavuz, 2010), ikinci dil ediniminde çoklu ortam araçlarının deyim öğretimi üzerindeki etkisi sınayan (Li, Hew ve Choo, 2016; Sanaefifar, 2017) ve animasyonların farklı alanlardaki akademik başarı üzerindeki etkisini sınayan (Aslan Efe, 2015; Daşdemir ve Doymuş, 2012) çalışmalar olduğu görülmektedir. Buna karşın anadil eğitimi kapsamında, iletişimde ve kültür aktarımında büyük öneme sahip olan deyimlerin öğretilmesine yönelik animasyon gösterilerinin işlevini sınayan herhangi bir araştırmaya rastlanmamıştır. Bu yönüyle 
araştırmanın alanyazına katkı sağlayabileceği düşünülmektedir. Bu bağlamda çalışmanın amacı animasyon gösterilerinin öğrencilerin deyim öğrenimi üzerindeki etkisini belirlemektir. Bu amaç doğrultusunda araştırmanın temel problem cümlesi "Deyim öğreniminde animasyon gösterilerinin bir etkisi var midır?" biçiminde oluşturulmuştur. Araştırmanın alt problem cümleleri ise şunlardır:

1. Deney ve kontrol gruplarının ön test ve son test puanlarına ilişkin betimsel değerleri nasıl bir görünüm sergilemektedir?

2. Deney ve kontrol gruplarının ön test puanları arasında anlamlı bir fark var midır?

3. Deney ve kontrol gruplarının son test puanları arasında anlamlı bir fark var midir?

4. Deney grubunun ön test ve son test puanları arasında anlamlı bir fark var midir?

5. Kontrol grubunun ön test ve son test puanları arasında anlamlı bir fark var midir?

6. Deney grubunun kalıcılık testi ve son test puanları arasında anlamlı bir fark var midir?

7. Deney grubu öğrencilerinin deyim öğrenimleri üzerinde animasyonların nasıl bir etkisi olduğu ile ilgili görüşleri nelerdir?

8. Deney grubu öğrencilerinin animasyonların derse karşı motivasyonları üzerindeki etkisi ile ilgili görüşleri nelerdir?

\section{Yöntem}

\section{Araştırmanın Deseni}

$\mathrm{Bu}$ çalışma, animasyonların deyim öğretimindeki etkililiğini sınayan karma desenli bir araştırmadır. Karma araştırma, nicel ve nitel araştırma yaklaşım ve tekniklerinin tek bir çalışmada bütünleştirildiği, diğer bir deyişle bir araya getirdiği çalışmalardır (Johnson ve Christensen, 2014, s. 430). Nitel araştırma, gözlem, görüşme ve doküman analizi gibi nitel veri toplama yöntemlerinin kullanıldığı, algıların ve olayların doğal ortamda gerçekçi ve bütüncül bir biçimde ortaya konmasına yönelik nitel bir sürecin izlendiği araştırmadır (Yıldırım ve Şimşek, 2016, s. 41). Nitel araştırmada araştırmacılar; verileri inceler, onlardan bir anlam çıkarır ve veri kaynaklarını kapsayan kategorileri veya temaları belirler (Creswell, 2016, s. 186).

Araştırmanın nicel verilerini elde etmek için ön test son test kontrol gruplu seçkisiz desen kullanılmıştır. Bu desende kontrol ve deney olmak üzere iki grup belirlenir ve 
grupların uygulama öncesinde bağımlı değişkenle ilgili ölçümleri alınır. Uygulama sürecinde etkisi test edilen deneysel işlem, deney grubuna verilirken kontrol grubuna verilmez. Son olarak grupların bağımlı değişkene ilişkin ölçümleri tekrar test edilir (Büyüköztürk, Kılıç Çakmak, Akgün, Karadeniz ve Demirel 2016, s. 205).

\section{Çalışma Grubu}

Araştırmanın çalışma grubunu, 2017-2018 eğitim-öğretim yılının ikinci döneminde ortaokul 5. sınıfta öğrenim gören 130 öğrenci oluşturmuştur. Bu öğrencilerden 65 'i deney; 65'i kontrol grubunda yer almıştır.

\section{İşlem Basamakları}

\section{Hazırlık}

Animasyonların deyim öğrenimi üzerindeki etkililiğin sınandığı bu çalışma için animasyonları bulunan 22 deyim belirlenmiştir. Deyimlerin düzeye uygunluğu ve animasyonların anlaşılabilirliği konularında alan uzmanlarının görüşüne başvurulmuştur. $\mathrm{Bu}$ görüşlerden hareketle deyim ve animasyon sayısı 16'ya düşürülmüştür. Araştırmada kullanılan animasyonların 12'si "Koray Varol Akademi”" tarafından hazırlanmıştır. $\mathrm{Bu} 12$ ve diğer 4 animasyonun ulaşım linkleri kaynakça bölümünde belirtilmiştir. Ayrıca animasyonların kullanılması için ilgili yerlerden gerekli izinler alınmıştır. Araştırmanın ön test ve son test verilerini elde edebilmek amacıyla araştırmacılar tarafından bu deyimlere ilişkin 16 sorudan oluşan çoktan seçmeli bir test geliştirilmiştir.

Araştırmanın uygulama bölümüne geçmeden önce 2017-2018 öğretim yılında, gerekli izinler alınarak, İstanbul ilindeki bir ortaokulda 5. sınıfa devam eden 130 ögrrenci belirlenmiş ve bu öğrencilerden deney ve kontrol grubu oluşturulmuştur.

\section{Ön test}

Araştırmacılar tarafindan geliştirilen 16 soruluk çoktan seçmeli test deney ve kontrol grubuna ön test olarak uygulanmıştır.

\section{Denel işlemler}

Denel işlemler sürecinde 16 deyim, her hafta 4'ü olmak üzere, 4 hafta boyunca öğrencilere ders öğretmenleri tarafından öğretilmeye çalışılmıştır. Bu süreçte deney grubu öğretmeni hazırlanan animasyonlardan; kontrol grubu öğretmeni ise sadece düz anlatım tekniğinden yararlanmıştır.

\section{Son test}

Sürecin sonunda araştırmacılar tarafından geliştirilen 16 soruluk çoktan seçmeli test deney ve kontrol grubuna son test olarak uygulanmıştır. 


\section{Verilerin Toplanması ve Çözümlenmesi}

Çalışmanın nicel verileri, deyim bilgisini ölçmek üzere araştırmacılar tarafından hazırlanmış çoktan seçmeli sorulardan oluşan bir test aracılığıyla toplanmıştır. Bu testte animasyonu gösterilen deyimlere yönelik 16 çoktan seçmeli soru bulunmaktadır. Sorular test hazırlama adımlarına göre oluşturulmuştur. Hem test hazırlama teknikleri hem de testin dil bütünlüğü konusunda alan uzmanlarının görüşlerinden yararlanılmıştır. Çoktan seçmeli deyim testinde yer alan her bir sorunun doğru cevabı animasyon ile öğretilen deyimlerden biri olacak biçimde ayarlanmıştır. Testte kullanılan çeldiricilerin 5. sınıf Türkçe ders kitabında yer alan deyimlerden oluşmasına dikkat edilmiştir.

Çalışmanın nitel verileri ise araştırmacılar tarafından oluşturulmuş iki soruluk yarı yapılandırılmış görüşme formu aracılığıyla elde edilmiştir. Yarı yapılandırılmış görüşme formuna ilişkin üç alan uzmanına danışılmış ve uzmanlardan gelen dönütler doğrultusunda sorulara son biçimi verilmiştir.

Yapılandırılmış görüşme formu aracılığıyla öğrencilerden yazılı olarak toplanan verilerin çözümlenmesinde, nitel araştırma yöntemlerinden betimsel çözümleme yöntemi kullanılmıştır. Betimsel çözümleme yaklaşımında veriler araştırma sorularının ortaya çıkardığı temalara göre düzenlenebileceği gibi, görüşme sürecinde kullanılan sorular ya da boyutlar dikkate alınarak da sunulabilir. Betimsel çözümlemede katılımcıların görüşlerini çarpıcı bir biçimde yansıtmak amacıyla doğrudan alıntılara sık sık yer verilir (Yıldırım ve Şimşek, 2016, s. 239). Çalışmada, görüşme sorularına verilen yanıtlar doğrultusunda temalar ve alt temalar oluşturulmuş ve bu temalar kapsamında değerlendirilmesi olanaklı görüşlerin katılımcı sayısı belirtilmiştir. Temalar kapsamında sayısı yüksek olan görüşlere ilişkin katılımcılardan doğrudan alıntılar yapılmıştır. Çalışmada, doğrudan alıntılarda katılımcı ismi yerine öğrenci 3 (Ö.3), öğrenci 21 (Ö.21) biçiminde kısaltma ve kodlama yapılmıştır.

Araştırmadan elde edilen nicel veriler, SPSS 20.0 programı kullanılarak çözümlenmiştir. Verilerin çözümlenmesinde deney ve kontrol grupları arasındaki ilişkilerin belirlenmesinde Mann-Whitney U testinden; aynı grubun ön test ve son test verileri arasındaki ilişkilerin belirlenmesinde ise Wilcoxon İşaretli Sıralar testinden yararlanılmıştır. Çalışmada anlamlılık düzeyi 0,05 olarak belirlenmiştir.

\section{Bulgular ve Yorum}

Bu bölümde animasyonların deyim öğrenimi üzerindeki etkisini belirlemek amacıyla uygulanan ön test ve son testten elde edilen verilerin istatiksel çözümlemelerine ve deney grubu öğrencilerine uygulanan yarı yapılandırılmış görüşme formunda yer alan sorulara verilen yanıtlara dayalı bulgulara yer verilmiştir. 


\section{Deney ve Kontrol Gruplarının Ön Test ve Son Test Puanlarına İlişkin Betimsel Değerleri Nasıl Bir Görünüm Sergilemektedir?}

Tablo 1.

Deney ve Kontrol Gruplarının Ön Test ve Son Test Puanlarına Illişkin Betimsel Değerleri

\begin{tabular}{ccccc}
\hline \multicolumn{2}{c}{ Gruplar } & n & $\overline{\mathbf{x}}$ & ss \\
\hline \multirow{2}{*}{ Deney } & Ön test & 65 & 43,4615 & 15,10182 \\
\cline { 2 - 5 } & Son test & 65 & 57,6154 & 18,60586 \\
\multirow{2}{*}{ Kontrol } & Ön test & 65 & 42,7692 & 16,05729 \\
& Son test & 65 & 45,0769 & 17,39909 \\
\hline
\end{tabular}

Tablo 1'de deney ve kontrol grubundaki öğrencilerin ön ve son testlerden aldıkları ortalama ve standart sapma puanlarının dağılımı gösterilmiştir. Buna göre deney grubu öğrencilerinin ön test ve son test ortalama puanları arasında yaklaşık 14 puanlık son test lehine; kontrol grubu öğrencilerinin ön test ve son test ortalama puanları arasında yaklaşık 3 puanlık son test lehine artış gösterdiği görülmektedir.

\section{Deney ve Kontrol Gurupları Ön Test Puanları Arasında Anlamlı Bir Fark Var Midır?}

Tablo 2.

Deney ve Kontrol Gurubunun Ön Test Puanlarına Illişkin Mann-Whitney U Testi Sonuçları

\begin{tabular}{cccccc}
\hline Ön test & $\mathbf{n}$ & $\begin{array}{c}\text { Sira } \\
\text { ortalamas }\end{array}$ & $\begin{array}{c}\text { Siralar } \\
\text { toplamı }\end{array}$ & $\mathbf{U}$ & $\mathbf{p}$ \\
\hline Deney grubu & 65 & 65.49 & 4257.00 & 2112 & .998 \\
Kontrol grubu & 65 & 65.51 & 4258.00 & 212 & \\
\hline
\end{tabular}

Araştırmaya katılan deney ve kontrol grubu öğrencilerinin ön test puanları arasında anlamlı bir ilişki olup olmadığını belirlemek için öncelikle verilerin normallik analizi yapılmış ve verilerin normal dağılmadığı $(p<0,05)$ belirlenmiştir. Yapılan Mann-Whitney U testi sonucunda deney ve kontrol gruplarının ön test puanları arasında anlamlı bir fark olmadığı $(\mathrm{p}>0,05)$ bulgulanmıştır.

\section{Deney ve Kontrol Gruplarının Son Test Puanları Arasında Anlamlı Bir Fark Var Midır?}

Tablo 3.

Deney ve Kontrol Grubunun Son Test Puanlarına İlişkin Mann-Whitney U Testi Sonuçları

\begin{tabular}{cccccc}
\hline Son test & $\mathbf{n}$ & $\begin{array}{c}\text { Sira } \\
\text { ortalamas }\end{array}$ & $\begin{array}{c}\text { Siralar } \\
\text { toplamı }\end{array}$ & $\mathbf{U}$ & $\mathbf{p}$ \\
\hline Deney grubu & 65 & 79.08 & 5140.50 & \multirow{2}{*}{1229.50} & \multirow{2}{*}{.000} \\
Kontrol grubu & 65 & 51.92 & 3374.50 & & \\
\hline
\end{tabular}


Araştırmaya katılan deney ve kontrol grubu öğrencilerinin son test puanları arasında anlamlı bir ilişki olup olmadığını belirlemek için öncelikle verilerin normallik analizi yapılmış ve verilerin normal dağılmadığı $(\mathrm{p}<0,05)$ belirlenmiştir. Yapılan Mann-Whitney U testi sonucunda deney ve kontrol gruplarının son test puanları arasında deney grubu lehine anlamlı bir fark olduğu $(\mathrm{p}<0,05)$ bulgulanmıştır.

\section{Deney Grubunun Ön Test ve Son Test Puanları Arasında Anlamlı Bir Fark Var Mıdır?}

Tablo 4.

Deney Grubunun Ön Test ve Son Test Puanlarının Wilcoxon Işaretli Stralar Testi Sonuçları

\begin{tabular}{ccccccc}
\hline Grup & Ön test-son test & $\mathbf{n}$ & Sıra ortalamasi & Sira toplamı & $\mathbf{z}$ & $\mathbf{p}$ \\
& negatif sıra & 6 & 28.50 & 171.00 & & \\
Deney & pozitif sıra & 55 & 31.27 & 1720.00 & -5.58 & .000 \\
& eşit & 4 & & & & \\
\hline
\end{tabular}

Deney grubunun ön test ve son test sonuçlarının anlamlı bir farklılık gösterip göstermediğini belirlemek için öncelikle verilerin normallik analizi yapılmış ve verilerin normal dağılmadığı $(\mathrm{p}<0,05)$ belirlenmiştir. Bu bağlamda yapılan Wilcoxon İşaretli Sıralar Testi sonuçları Tablo 4'te verilmiştir. Buna göre, deney grubunun ön test ve son test puanları arasında son test lehine anlamlı bir fark olduğu görülmektedir $(\mathrm{p}<0,05)$.

\section{Kontrol Grubunun Ön Test ve Son Test Puanları Arasında Anlamlı Bir Fark Var Mıdır?}

Tablo 5 .

Kontrol Grubunun Ön Test ve Son Test Puanlarının Wilcoxon İşaretli Sıralar Testi Sonuçları

\begin{tabular}{ccccccc}
\hline Grup & Ön test-son test & $\mathbf{n}$ & Sıra ortalaması & Sira toplamı & $\mathbf{z}$ & $\mathbf{p}$ \\
\hline \multirow{3}{*}{ Kontrol } & negatif sıra & 22 & 23.41 & 515.00 & & \\
& pozitif sira & 30 & 28.77 & 863.00 & -1.602 & .109 \\
& eşit & 13 & & & & \\
\hline
\end{tabular}

Kontrol grubunun ön test ve son test sonuçlarının anlamlı bir farklılık gösterip göstermediğini belirlemek için öncelikle verilerin normallik analizi yapılmış ve verilerin normal dağılmadığg $(\mathrm{p}<0,05)$ belirlenmiştir. Bu bağlamda yapılan Wilcoxon İşaretli Sıralar Testi sonuçları Tablo 5'te verilmiştir. Buna göre, kontrol grubunun ön test ve son test puanları arasında anlamlı bir fark olmadığı görülmektedir $(\mathrm{p}>0,05)$. 


\section{Deney Grubunun Kalıcılık Testi ve Son Test Puanları Arasında Anlamlı Bir Fark Var Mıdır?}

Tablo 6.

Deney Grubunun Son Test ve Kalıcılık Testi Puanlarına İlişkin Wilcoxon İșaretli

Stralar Testi Sonuçları

\begin{tabular}{ccccccc}
\hline Grup & Son test- kalıcılık t. & $\mathbf{n}$ & Sıra ortalaması & Sıra toplamı & $\mathbf{z}$ & $\mathbf{p}$ \\
\hline \multirow{3}{*}{ Deney } & negatif sıra & 29 & 22.60 & 655.50 & & \\
& pozitif sıra & 15 & 22.30 & 334.50 & -1.909 & .056 \\
& eşit & 21 & & & & \\
\hline
\end{tabular}

Deney grubunun son test ve kalıcılık testi sonuçlarının anlamlı bir farklılık gösterip göstermediğini belirlemek için öncelikle verilerin normallik analizi yapılmış ve verilerin normal dağılmadığı $(\mathrm{p}<0,05)$ belirlenmiştir. Yapılan Wilcoxon İşaretli Siralar Testi sonuçları Tablo 6'da verilmiştir. Tablo 6 incelendiğinde, deney grubunun son test ve kalıcılık testi puanları arasında anlamlı bir fark olmadığı görülmektedir $(\mathrm{p}>0,05)$.

\section{Deney Grubu Öğrencilerinin Deyim Öğrenimleri Üzerinde Animasyonların Nasıl Bir Etkisi Olduğu İle İlgili Görüşleri Nelerdir?}

Tablo 7.

Deney Grubu Öğrencilerinin Animasyonların Deyim Öğrenimleri Üzerindeki Etkisine Illişkin Görüssleri

\begin{tabular}{lcc}
\hline \multicolumn{1}{c}{ Görüşler } & f & $\mathbf{\%}$ \\
\hline Deyimleri öğrenmemde animasyonların olumlu yönde katkısı oldu. & 58 & 89 \\
\hline Deyimleri öğrenmemde animasyonların herhangi bir katkısı olmadı. & 7 & 11 \\
\hline
\end{tabular}

Tablo 7 incelendiğinde araştırmanın deney grubunu oluşturan öğrencilerin yaklaşık \%89'u animasyonların deyim öğrenmelerine olumlu yönde katkısının olduğu görüşünü destekledikleri görülmektedir. Deney grubunu oluşturan öğrencilerin yaklaşı \% \%11'i ise animasyonların deyimleri öğrenmelerine herhangi bir katkısının olmadığı görüşündedir. Animasyonların deyim öğrenimi üzerindeki etkisine ilişkin bazı öğrenci görüşleri aşağıda verilmiştir:

Ö.6: "Ben, animasyon sayesinde deyimleri aklımda daha iyi tutabiliyorum. Unuttuğum zamanlarda hemen animasyondaki kişiler geliyor aklıma. Yani ben animasyon sayesinde daha iyi öğrendim.”

Ö.17: "Ben daha iyi öğrendim. Sınavlarda çok etkisi oldu. Daha iyi anladım. Daha iyi kavradım."

Ö.22: "Daha iyi öğrendim. Çünkü daha açıkça ve deyimlerin insan üzerinde nasıl bir etki yarattığını öğrendim." 
Ö.26: "Daha iyi öğrendim. Bir etkisi oldu. Bu sayede sınavlarda daha başarılı olurum ve yüksek not alırım. Bu sayede öğretmenimin gözüne girerim.”

Ö.39: “Aslında bilmediğim çok deyim oldu. Bana da yenilik oldu. Öğrendiğim çok iyi oldu. Çünkü ilerideki sınavlarda çıkabilir."

Ö.54: "Bence animasyonlarla deyimler daha çok eğlenceli bir hâl almaya başladı. Bir de eskiden cümle içinde deyim kullanmaya çalışırdım ama yine de başarısız olurdum. Şimdi az da olsa kullanabiliyorum. Bazen eve gidince izlediğimiz şeyleri bir daha izlemeye çalışıyorum."

\section{Deney Grubu Öğrencilerinin Animasyonların Derse Karşı Motivasyonları Üzerindeki Etkisi İle İlgili Görüşleri Nelerdir?}

Tablo 8 .

Deney Grubu Öğrencilerinin Animasyonların Derse Karşı İlgileri Üzerindeki Etkisine İlişkin Görüşleri

\begin{tabular}{lcc}
\multicolumn{1}{c}{ Görüşler } & f & \% \\
\hline Animasyonlar derse karşı ilgimi artırdı. & 56 & 86 \\
\hline Animasyonların derse karşı ilgim üzerinde herhangi bir etkisi olmadı. & 9 & 14 \\
\hline
\end{tabular}

Tablo 8 incelendiğinde araştırmanın deney grubunu oluşturan öğrencilerin yaklaşık \%86'sı animasyonların derse karşı ilgilerinin artmasında olumlu katkısının olduğunu belirtmektedir. Deney grubunu oluşturan öğrencilerin yaklaşı $\% 14$ 'ü ise animasyonların derse karşı ilgi artırma konusunda herhangi bir etkisinin olmadığ görüşündedir. Animasyonların derse karşı ilgi üzerindeki etkisine ilişkin bazı öğrenci görüşleri aşağıda verilmiştir:

Ö.3: "Deyimleri animasyonlarla öğreneceğimize gerçekten sevindim ve bu animasyonlar derse karşı ilgimi daha çok artırdı."

Ö.6: "Deyimleri animasyonlarla öğreneceğimi duyduğumda çok mutlu olmuştum. Çünkü deyimleri öğrenirken hem eğlenecek hem de öğrenecektik."

Ö.17: "Deyimleri duyduğumda ilk başta çok etkilendim. Çok değişikler. Bana bunları hissettirdi. Derse karşı ilgimi de artırdı. Deyimlerden sınav yaptık. Onda da daha anladığım sorular oldu."

Ö.32: "İlk olarak günlük hayatta sık sık animasyon izlerim. Benim için bir his oluşmadı. İkinci olarak da evet ilgim arttı. Eğer hocamız animasyon yerine sadece ses getirseydi o zaman olduğundan daha az heyecanım olurdu."

Ö.39: "Şaşırdım ama deyimler kolay gelir, dedim. Animasyon derse karşı ilgimi çekti. Tek okulda çalışmadım, test çözmedim; evde bile çözmeye başladım.”

Ö.51: "Evet ilgimi artırdı. Görerek ve izleyerek daha iyi anladığım için sevindim." 
Ö.60: "Animasyonlar ile nasıl sunulacağını merak ettim. Deyimleri aklımda canlandırarak hayal gücüm arttı."

\section{Tartışma, Sonuç ve Öneriler}

Araştırmanın temel amacı animasyonların deyim öğretimi üzerindeki etkisini belirlemekti. Bu bağlamda yapılan istatistiksel analizler, animasyonların deyim öğrenimini olumlu yönde ve istatistiksel olarak anlamlı düzeyde etkilediğini; buna karşın geleneksel anlayışla yapılan öğretimin deyim öğrenimi üzerinde istatistiksel olarak anlamlı bir etkisinin olmadığını ortaya koymuştur. Sanaefifar'ın (2017) ikinci dil ediniminde yapmış olduğu bir çalışmada, animasyon kullanımının deyim öğrenimine olumlu etkisinin olduğu sonucu ortaya çıkmıştır. Bu araştırmadan elde edilen bulgular, Sanaefifar'ın (2017) bulgusunu destekler niteliktedir. Benzer biçimde Mayers ve Anderson (1992), konunun işlenmesi sırasında animasyonlardan yararlanmanın öğrencilerin resim ve kelimeler arasında ilişki kurarak problem çözme başarımları üzerinde olumlu bir etkisinin olduğu sonucuna ulaşmışlardır. Ünal ve Bursalı (2015) tarafindan yapılan çalışmada da çoklu ortam araçlarından çizgi dizilerin öğrencilerin söz varlığına olumlu yönde katkı sağladığı sonucu elde edilmiştir. Hayran (2010), çok uyaranlı eğitim ortamlarının kavram gelişimi ve kavram gelişiminin kalıcılığı üzerinde, yürürlükteki yaklaşıma göre daha etkili olduğunu saptamıştır. Mürsel (2009), karikatürlerin deyim ve atasözlerinin öğretiminde etkili bir materyal olduğunu bulgulamıştır. $\mathrm{Bu}$ sonuçlar değerlendirildiğinde animasyon veya diğer çoklu ortam araçlarının hem dil edinimi hem de problem çözme ve ilişkilendirme gibi görece üst düzey bilişsel becerilerin gelişiminde etkili öğrenme-öğretme materyalleri olduğu söylenebilir.

Animasyonla gerçekleştirilen deyim öğretiminin kalıcılığına yönelik yapılan istatistiksel analizler sonucunda elde edilen bulgu, animasyonların deyim bilgisinde kalıcılığı sağladığı yönündedir. Nitekim ilgili alanyazın incelendiğinde çoklu ortamda öğrenmenin daha etkili ve kalıcı olduğu sonucuna ulaşan birçok çalışma bulunmaktadır (Arslan, 2008; Koç, Şimşek ve Has, 2013; Raupers, 2000; Tsoua, Wang ve Tzeng, 2006; Yılmaz ve Akkoyunlu, 2006; Yılmaz ve Dinçol Özgür, 2012).

Öte yandan araştırmanın nitel boyutunda öğrenci görüşlerine yönelik yapılan betimsel analizler, araştırmaya katılan öğrencilerin büyük bir çoğunluğunun animasyonların deyim öğrenimlerine olumlu yönde katkısının olduğu ve derse karşı ilgilerini artırdığı yönünde görüş bildirdiğini ortaya koymuştur. Kaya ve Çengelci (2011) tarafından öğretmen adaylarının sosyal bilgiler eğitiminde filmlerden yararlanılmasına ilişkin görüşlerini belirlemek amacıyla yapılan çalışmada; öğretmen adaylarının filmlerin öğrenme-öğretme sürecinde birden çok duyu organına hitap ettiği, kalıcı ve eğlenceli bir öğrenmeye destek sağladığı biçiminde görüş bildirdikleri sonucuna varılmıştır. Benzer bir biçimde Yünkül ve Er (2014) çoklu ortam yazılımının öğrencilerin derse yönelik tutumlarına olumlu yönde anlamlı bir etkisinin olduğunu bulgulamışlardır. Bu iki araştırmadan elde edilen bulgular bu araştırmanın 
sonuçları ile örtüşmektedir. Bu konuyla ilgili olarak Akkoyunlu ve Yılmaz (2005), öğretim teknolojisi kullanılarak hazırlanan öğrenme ortamlarının çeşitli kaynaklar ile öğrenme-öğretme ortamlarını daha çok duyuya hitap eden çevreler haline getirerek, öğrenci motivasyonunu ve başarısını artırdığını belirtmiştir.

Eleştirel düşünme ile akademik yazmanın alt boyutları arasındaki ilişkiye bakıldığında en yüksek ilişkinin sözcük seçiminde olduğu görülmektedir. Yazılı bir metinde sözcük seçimi, okurun dikkatinin yazıya çekilmesi açısından önemli bir boyuttur. Uygun ve etkili sözcük seçen yazarlar, okur özelliklerini dikkate alan yazarlardır. Dolayısıyla sözcük seçimindeki başarı, düşünme becerisinin göstergelerinden biridir (Bayat, 2014). Sözcük seçimi bağlamında deyim kullanımı, hem düşünme becerilerinin bir göstergesi olarak hem de yazılı anlatımı güçlendirmesi ve okurun dikkatini çekmesi açısından önemlidir. Araştırmadan elde edilen animasyonların deyimler üzerinde etkili ve kalıcı bir öğrenme sağladığı yönündeki bulgular, animasyonların deyim, atasözü ve kalıp sözlerin öğretimi sürecinde etkin bir biçimde işe koşulması gerektiğini göstermektedir.

Deyimlerin öğretilmesi sürecinde; doğal sözcük öğretimi içerisinde bağlamdan hareketle deyimin anlamını tahmin etme, sözlük kullanma, sınıf içi drama etkinlikleri, geniş ve bağımsız okumalar yapma gibi çeşitli stratejiler animasyonlarla eşzamanlı olarak işe koşulabilir. Ayrıca bireyi öğrenme sürecinde daha aktif ve istekli kılmak adına yapılacak uygulamalar, gelişen eğitim teknolojileri ışı̆̆ında sürekli yenilenip geliştirilerek çeşitlendirilmelidir. Nitekim, etkili bir öğrenme sürecinin planlanması, yaşam boyu bireyin öğrenmeyi zevkli bir süreç olarak algılamasına ve kaliteli öğrenme yaşantıları oluşturmasına katkı sağlayacaktır.

\section{Kaynakça}

Akkoyunlu, B. \& Yılmaz, M. (2005). Türetimci çoklu ortam öğrenme kuramı. Hacettepe Üniversitesi Eğitim Fakültesi Dergisi, 28(28), 9-18.

Arslan, Ö. (2008). İlköğretim 8. sınıf TC İnklâp Tarihi ve Atatürkçülük dersi öğretiminde görsel ve işitsel materyal kullanımının öğrencilerin akademik başarıları ve hatırda tutma düzeyleri üzerindeki etkisi (Yüksek lisans tezi). Dokuz Eylül Üniversitesi, İzmir.

Aslan Efe, H. (2015). Animasyon destekli çevre eğitiminin akademik başarıya, akılda kalıcılığa ve çevreye yönelik tutuma etkisi. Bilgisayar ve Eğitim Araştırmaları Dergisi, 3(5), 130143.

Bayat, N. (2014). Öğretmen adaylarının eleştirel düşünme düzeyleri ile akademik yazma başarıları arasındaki ilişki. Eğitim ve Bilim, 39(173), 155-168.

Bayat, N. \& Çetinkaya, G. (2014). Tanınırlık ve saydamlık derecesi bakımından deyimlerin anlaşılabilirliği. Adıyaman Üniversitesi Sosyal Bilimler Enstitüsü Dergisi, (17), 205-232.

Bilgin, M. (2013). Anlamdan anlatıma Türkçemiz (3. Baskı). Ankara: Anı Yayıncılık.

Bulut, S. (2017). 101 deyim 101 öykü (5. Baskı). İstanbul: Can Çocuk. 
Büyüköztürk, Ş., Kılıç Çakmak, E., Akgün, Ö.E., Karadeniz, Ş. \& Demirel F. (2016). Bilimsel araştırma yöntemleri (21. Baskı). Ankara: Pegem Akademi.

Cacciari, C. \& Tabossi, P. (1988). "The comprehension of idioms". Journal of Memory and Language, 27(6), 668-683.

Creswell, J.W. (2016). Araştırma deseni: Nitel, nicel ve karma yöntem ve yaklaşımları (2. Bask1), Selçuk Beşir Demir (Çev. Ed.), Ankara: Eğiten Kitap.

Daşdemir, İ. \& Doymuş K. (2012). Fen ve Teknoloji dersinde animasyon kullanımının öğrencilerin akademik başarılarına, öğrenilen bilgilerin kalıcılığına ve bilimsel süreç becerilerine etkisi. Pegem Ĕ̈itim ve Ögretim Dergisi, 2(3), 33-42.

Göçmenler, G. (2002). Uzaktan eğitim teknolojileri ve çağdaş yönelimler. Sakarya Üniversitesi Eğitim Fakültesi Dergisi, 4, 164-175.

Güneş, S. (2009). Yabanc1 dil öğretiminde deyim öğretimi: yöntemler, teknikler ve uygulamalar. Dilbilim, 2(2), 59-78.

Güvercin, Z. (2010). Fizik dersinde simülasyon destekli yazllımın öğrencilerin akademik başarısına, tutumlarına ve kalıcılığa olan etkisi (Yüksek lisans tezi). Çukurova Üniversitesi, Adana.

Hayran, Z. (2010). Çok uyaranlı eğitim ortamlarının öğrencilerin kavram gelişimine etkisi. Eğitim ve Bilim, 35(158), 128-142.

Johnson, B. \& Christensen, L. (2014). Ĕgitim araştırmaları: Nicel, nitel ve karma yaklaşımlar (4. Baskı) S. B. Demir (Çev. Ed.), Ankara: Eğiten Kitap.

Freeman, D.L. \& Anderson, M. (2014). Dil öğretiminde teknik ve ilkeler (3. Bask1). Mehrali Calp (çev.). Ağrı: Ağrı İbrahim Çeçen Üniversitesi Yayınları.

Kaya, E. \& Çengelci, T. (2011). Öğretmen adaylarının sosyal bilgiler eğitiminde filmlerden yararlanılmasına ilişsin görüşleri. Journal Of Social Studies Education Research,2(1), 116-135.

Koç, Y., Şimşek, Ü. \& Has, C. (2013). Iş̧ı ünitesinin öğretiminde bilgisayar animasyonlarının etkisi. Muş Alparslan Üniversitesi Fen Bilimleri Dergisi, 1(2), 145-156.

Langlotz, A. (2006). Idiomatic creativity: A cognitive-linguistic model of udiomrepresentation and idiom-variation in English (Vol. 17). Amsterdam, Philadelphia: John Benjamins Publishing Company.

Li, E.H., Hew, S.H. \& Choo, S.H. (2016). The learning of Chinese idioms through multimedia storytelling prototype. Journal of Educational Multimedia and Hypermedia, 25(1), 37-52.

Lowe, R.K. (2004). Animation and learning: Value for money? In R. Atkinson, C. McBeath, D. Jonas-Dwyer and R. Phillips (Eds.), Beyond the comfort zone: Proceedings of the 21st ASCILITE Conference (pp. 558-561). Perth.

McCarthy, M., O'Keeffe, A. \& Walsh, S. (2010). Vocabulary matrix: Understanding, learning, teaching. United Kingdom: Cengage Learning. 
Mayer, R.E. \& Anderson, R.B. (1992). The instructive animation: Helping students build connections between words and pictures in multimedia learning. Journal of Educational Psychology, 84(4), 444-452.

Mayer, R.E. \& Moreno, R. (2002). Animation as an aid to multimedia learning. Educational Psychology Review, 14, 87-99.

Mürsel, C.G. (2009). Deyim ve atasözlerinin öğretiminde karikatürün etkisi (Yayınlanmamış yüksek lisans tezi). Ankara Üniversitesi, Ankara.

Raupers, P.M. (2000). Effects of accommodating learning-style preferences on long-term retention of technology training content. In National Forum of Applied Educational Research Journal, 13(2), 23-26.

Sağır, M. \& Demir Atalay, T. (2016). Etkinliklerle dil bilgisi ögretimi. Ankara: Pegem Akademi.

Sanaeifar, S.H. (2017). The effect of watching English language animation movies on learning idioms: A case of Iranian EFL learners. European Journal of English Language Teaching, 2(3), 20-38.

Şirin, E., Işık, S., Çevik, C., Doğru, T., Dalkıç, T. \& Solar, B. (2017). Deyim yerindeyse. Yusuf Doğan (Ed.). Ankara: Pegem Akademi.

Tompkins, G. (2005). Language arts: Patterns of practice (6. Press). Upper Saddle River, NJ: Pearson Prentice Hall.

Tran, H.Q. (2012). An explorative study of idiom teaching for pre-service teachers of English. English Language Teaching, 5(12), 76.

Tsou, W., Wang, W. \& Tzeng, Y. (2006). Applying a multimedia storytelling website in foreign language learning. Computers \& Education, 47(1), 17-28.

Ünal, F.T. \& Bursalı, H. (2015). Çizgi dizilerle kalıp (ilişki) söz öğretimi: Cille örneği. Akademik Sosyal Araştırmalar Dergisi, 3(12), 69-83.

Williams, L., Bannister, C., Arribas-Ayllon, M., Preece, A. \& Spasic, ' I. (2015). The role of idioms in sentiment analysis. Expert Systems with Applications, 42(21), 7375-7385.

Yavuz, N. (2010). Yabancı dilde deyimlerin öğretimi için bir araç geliştirme denemesi. Dil Dergisi, 147, 7-21.

Yıldırım, A. \& Şimşek H. (2016). Sosyal bilimlerde nitel araştırma yöntemleri (10. Baskı). Ankara: Seçkin Yayıncılık.

Yılmaz, A. \& Özgür, S. D. (2012). Türetimci çoklu ortamın öğretmen adaylarının öğrenme stillerine göre başarı, tutum ve kalıcılığa etkisi. Hacettepe Üniversitesi Ĕ̆itim Fakültesi Dergisi, 42, 441-452.

Yılmaz, F. \& Talas, Y. (2015). Yabancı dil olarak Türkçe öğretiminde materyal olarak animasyon kullanımı ve önemi. International Journal Of Languages' Education And Teaching, 3(1), 114-127.

Yılmaz, M. \& Akkoyunlu, B. (2006). Farklı öğrenme ortamlarının kalıcılığa etkisi. Eurasian Journal of Educational Research, 23, 209-218. 
Yünkül, E. \& Er, K.O. (2014). Çoklu ortam yazılımının derse yönelik tutuma etkisi. Eğitimde

Kuram ve Uygulama, 10(2), 316-330.

\section{Araştırmada kullanılan animasyonlara aşağıdaki linklerden ulaşılabilir:}

- $\quad$ https://www.youtube.com/watch?v=_89XAUCgvRI (abayı yakmak)

- $\quad$ https://www.youtube.com/watch?v=-OZ-IjskW3U (burnunun dikine gitmek)

- $\quad$ https://www.youtube.com/watch?v=xwJiV6Q4HrI (ayıkla pirincin taşını)

- $\quad$ https://www.youtube.com/watch?v=A97KLMESAFs (elinin hamuru ile erkek işine...)

- $\quad$ https://www.youtube.com/watch?v=d_6FM8MRMLY\&index=1\&list=PL72FSIxrb WumpQiOVIrYhE2u0pqVaX8E1 (kulak kabartmak)

- $\quad$ https://www.youtube.com/watch?v=_Msgn13SbwA\&list=PL72FSIxrbWumpQiOV $\underline{\operatorname{IrYhE} 2 \mathrm{u} 0 \mathrm{pqVaX} 8 \mathrm{E} 1 \& \text { index }=2}$ (ipe un Sermek)

- $\quad$ https://www.youtube.com/watch?v=V7acq5CibM\&index=3\&list=PL72FSIxrbWumpQiOVIrYhE2u0pqVaX8E1 (yumurta kapıya dayanmak)

- $\quad$ https://www.youtube.com/watch?v=5tAhw1KwrU\&list=PL72FSIxrbWumpQiOVIrYhE2u0pqVaX8E1\&index=4 (gözüne uyku girmemek)

- $\quad$ https://www.youtube.com/watch?v=n2K6vAPWWKg\&index=6\&list=PL72FSIxrb WumpQiOVIrYhE2u0pqVaX8E1 (göze girmek)

- $\quad$ https://www.youtube.com/watch? $\mathrm{v}=$ MScnBDiWUdM\&index=5\&list=PL72FSIxrb WumpQiOVIrYhE2u0pqVaX8E1 (gözü yükseklerde olmak)

- $\quad$ https://www.youtube.com/watch?v=5ruTtc0AJ_s\&index=7\&list=PL72FSIxrbWum pQiOVIrYhE2u0pqVaX8E1 (ağzı kulaklarına varmak)

- $\quad$ https://www.youtube.com/watch?v=YtZU1y6Vq0\&list=PL72FSIxrbWumpQiOVIrYhE2u0pqVaX8E1\&index=8 (zevkten dört köşe olmak)

- https://www.youtube.com/watch?v=a Zd4f6aAXE\&index=9\&list=PL72FSIxrbWu mpQiOVIrYhE2u0pqVaX8E1 (ince eleyip sik dokumak)

- $\quad$ https://www.youtube.com/watch?v=FzBuPZiCqdY\&index=10\&list=PL72FSIxrbW umpQiOVIrYhE2u0pqVaX8E1 (tası tarağı toplamak)

- $\quad$ https://www.youtube.com/watch?v=ZHGy6QKe-

JI\&index=11\&list=PL72FSIxrbWumpQiOVIrYhE2u0pqVaX8E1 (göklere çıkarmak)

- $\quad$ https://www.youtube.com/watch?v=SaHnsqH3gtY (ateş pahası olmak)

\section{Extended Abstract}

When the literature is reviewed; some other researches on area could have found that examines the influence of multimedia tools (such as animations, cartoons, etc) in language skills (Ünal and Bursalı, 2015; Y1lmaz and Talas, 2015), investigates the use of and teaching of idioms (Bayat and Çetinkaya, 2014; Güneş, 2009; Tran, 2012; Williams, Bannister, Arribas-Ayllon, Preece and Spasic, 2015; Yavuz, 2010), tests the effect of multimedia tools on teaching an idiom in the acquisition of second language (Li, Hew and Choo, 2016; Sanaefifar, 2017), searches the effects of animations on academic achievement in different fields (Aslan Efe, 2015; Daşdemir 
and Doymuş, 2012). However, within the context of mother tongue education, no research was found to test the functioning of animations to teach phrases that have a great deal of importance in communication and culture transfer. It is believed that research in this direction can contribute to the field.

In the study, a mixed method design of both quantitative and qualitative research methods was adopted. The sampling of the study is composed of 130 students who are in fifth grade in 2017-2018 school year. During the teaching of the idioms, the experimental group was teaching by animations and the control group was utilized within a straightforward narrative technique just as framework of the traditional approach. Multiple choice test as a quantitative data collection tool and semistructured interview form as a qualitative data collection tool, were used. The MannWhitney $U$ test and the Wilcoxon Marked Rank test were used to analyze the quantitative data obtained; descriptive analysis method is used in the analysis of qualitative data.

The main purpose of the study was to determine the effect of the animations on the teaching of the idiom. Statistical analyzes in this context show that animations have a positive and statistically significant effect on language learning. On the other hand, it has been revealed that there is no effect on the idiomatic learning of teaching with traditional understanding. In a study that SanaefiFar (2017) made in acquiring a second language, the end result was that the use of animation was a positive influence on the learning of idioms. Findings obtained from this research support the finding of Sanaefifar (2017). Similarly, Mayers and Anderson (1992) concluded that the use of animations during the processing of the subject had a positive effect on problem solving achievement by correlating the pictures and words. Unal and Bursal (2015) also made the result that the line sequences from the multimedia tools contributed positively to students' vocabulary. When these results are evaluated, it can be said that animation or other multimedia tools are effective learning-teaching materials in the development of relatively high level cognitive skills such as language acquisition and problem solving and association

As a result of the statistical analysis made for the permanency of the teaching of the idiom which is carried out with animation, the finding obtained is that the animations provide permanence in the idiomatic knowledge. As a matter of fact, when several sources are reviewed there are a number of studies which have found that learning with multimedia is more effective and lasting (Arslan, 2008; Koç, Şimşek and Has, 2013; Raupers, 2000; Tsoua, Wang and Tzeng, 2006; Y1lmaz and Akkoyunlu, 2006; Y1lmaz and Dinçol Özgür, 2012).

Descriptive analyzes of qualitative aspects of the research revealed that the vast majority of the students participating in the research reported that animations contributed positively to the teaching of idioms and that they increased their views towards the lesson. Kaya and Çengelci (2011) conducted a study aimed at determining the opinions of teacher candidates regarding the use of films in social studies 
education; teacher candidates have come to the conclusion that the films support a learning that is appealing to more than one sensory organ in the learning-teaching process and supports a lasting and entertaining learning. Similarly, Yünkül and Er (2014) found that multimedia software has a positive effect on students' attitudes toward the course positively. The findings from these two studies are in agreement with the results of this study. In this regard, Akkoyunlu and Y1lmaz (2005) stated that learning environments prepared by using instructional technology increase the motivation and success of students by making various learning environments and learning environments more sensible

When we look at subscales of the relationship between critical thinking and academic writing, it is seen that the highest correlation is in word choice. The choice of a word in a written text is an important dimension in terms of catching the reader's attention. Authors who choose appropriate and effective words are authors who take into consideration the characteristics of the reader. So success in word selection is one of the indicators of thinking ability (Bayat, 2014). The use of idiom in the context of word choice is important both as a demonstration of thinking skills as well as to reinforce written expression and draw attention to the reader. The findings of the research, which show that animations provide effective and lasting learning on idioms, show that animations must be actively executed in the process of teaching idioms, proverbs and phrases.

In the process of teaching the idioms; various strategies such as predicting the meaning of the idiom by contextual action within the natural word teaching, using a dictionary, classroom drama activities, and making large independent readings can be performed simultaneously with the animations. 